\title{
What the Agricultural Sector in Florida Needs to Know about Heat-Related IIIness (HRI) ${ }^{1}$
}

\author{
Paul Monaghan, Karissa Raskin, Maria Morera, Antonio Tovar, Valerie Mac, and Joan Flocks ${ }^{2}$
}

\section{Introduction}

While Florida's climate makes it ideal for growing a wide variety of crops, the intense heat and humidity can also pose significant dangers for those who work in agriculture. The Centers for Disease Control and Prevention (2008) concludes that crop workers face a risk of heat-related illness that is 20 times greater than that of other workers. With three of Florida's hottest years on record occurring in the past four years (NOAA, 2019), farm owners, their families, and employees need to be aware of the symptoms, treatment, and prevention of heat-related illness (HRI).

\section{Heat-Related IIIness (HRI)}

Heat-related illness is of particular concern in Florida, where summer days with extreme heat and humidity are a regular phenomenon. But high temperatures and humid conditions can happen even during the winter months, the peak season for crop production in the state (Morano, Watkins, \& Kintziger, 2016; Sheridan \& Lee, 2018). Heat-related illness can affect anyone, but there are higher risks for individuals performing strenuous physical activity, those who are not acclimated to the heat, those with chronic health issues, and those who may begin their workday without adequate hydration (Mac \& McCauley, 2017; Mix et al., 2018; NIOSH, 2016b). While most agricultural injuries are underreported, death from HRI stands out, and there are recent cases of farmworkers experiencing fatal heat stroke in Florida (Bureau of Labor Statistics, 2019: Morano, Watkins, \& Kintziger, 2016). Because HRI is preventable, this document will provide an introduction for Extension agents by focusing on the symptoms, risk factors, and treatments. It is the first in a series of documents on how Extension can address issues of safety among agricultural producers, their families, and their employees. Future publications will highlight simple prevention measures, such as handwashing, eye safety, and methods that Extension agents can use to promote behavior change leading to a healthier and more sustainable agricultural workplace.

Extension agents should be able to identify the factors that make farmers, agricultural workers, and family members most vulnerable to injury and use the information to identify preventative measures that can help reduce their clients' risk of HRI. By raising awareness of the severity of HRI and educating clients about HRI risk factors, symptoms, and safety practices, Extension agents can improve the health and safety of their clients and potentially save lives.

1. This document is AEC696, one of a series of the Department of Agricultural Education and Communication, UF/IFAS Extension. Original publication date August 2020. Visit the EDIS website at https://edis.ifas.ufl.edu for the currently supported version of this publication.

2. Paul Monaghan, associate professor, Department of Agricultural Education and Communication; Karissa Raskin, civic collaboration specialist, Department of Strategic Initiatives, City of Gainesville; Maria Morera, OPS professional, Department of Agricultural Education and Communication; Antonio Tovar, director, Farmworker Association of Florida; Valerie Mac, assistant professor, Neil Hodgson Woodruff College of Nursing, Emory University; and Joan Flocks, director, Social Policy Division, Center for Governmental Responsibility, Levin College of Law, University of Florida; UF/IFAS Extension, Gainesville, FL 32611.

The Institute of Food and Agricultural Sciences (IFAS) is an Equal Opportunity Institution authorized to provide research, educational information and other services

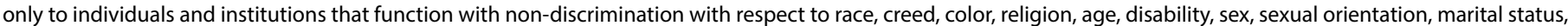

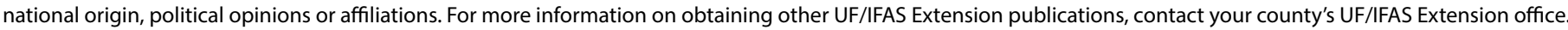
U.S. Department of Agriculture, UF/IFAS Extension Service, University of Florida, IFAS, Florida A \& M University Cooperative Extension Program, and Boards of County Commissioners Cooperating. Nick T. Place, dean for UF/IFAS Extension. 


\section{What is HRI?}

Heat-related illness refers to a spectrum of disorders that occur when heat is not sufficiently eliminated from the human body. The chemical and physiological processes that occur within the human body function optimally when an internal body temperature is within the range of $96^{\circ} \mathrm{F}$ to $100^{\circ} \mathrm{F}$ (Sund-Levander, Forsberg, \& Wahren, 2002). Because sweating is the primary method of eliminating heat from our bodies, when high humidity levels prevent the sweat from evaporating off our skin, cooling is not achieved, and our internal temperature continues to rise above normal limits. Excessive sweating will continue to the point of dehydration, negatively affecting one's physiological processes with symptoms of increasing severity, which can lead to heat stroke and even death (Jacklitsch et al., 2016; LugoAmador, Rothenhaus, \& Moyer, 2004). All agricultural workers are at risk, as well as operators driving a tractor; youth and family members working in high-temperature settings, such as greenhouses; and professional labor crews harvesting fruits and vegetables. In addition to heat stroke, HRI can stress the body (particularly kidney function) and contribute to accidents and injuries on the farm.

\section{Five Types of HRI and Associated Symptoms}

There are 5 main types of HRI: heat rash, heat syncope (fainting), heat cramps, heat exhaustion, and heat stroke (Knochel, 1989; NIOSH, 2016b). The most severe form of HRI is heat stroke, which can cause the body's internal temperature to rise to $106^{\circ} \mathrm{F}$ or higher within 10 to 15 minutes (NIOSH, 2016a). Heat stroke is not always preceded by the other stages and may occur without other symptoms. Heat exhaustion is the second most dangerous type of HRI and, if untreated, can lead to heat stroke. Recognizing heat exhaustion before it becomes heat stroke and taking steps to cool the body and recover is key to mitigating a critical medical emergency (Coris et al., 2006; Costrini, 1989). If symptoms of heat stroke are present, 911 should be called immediately so emergency medical personnel can transport the impacted individual to a medical site as quickly as possible (Rao, 2007). While waiting for help to arrive, bystanders should attempt to cool the impacted individual as quickly as possible by submersing them into cold water or applying ice packs or cool towels at the armpits, inner thighs, and head/neck area.

Table 1 has been adapted from other HRI-awareness resources (eXtension, 2016; Murphy, n.d.; NIOSH, 2016) as a tool to help Extension agents and their clients recognize the signs and symptoms of HRI, provide background on the physiological reason for why these symptoms are occurring, and offer recommended steps that can be taken to decrease HRI symptoms.

\section{What raises the risk factors for HRI?}

Metabolic processes and musculoskeletal movement allow the human body to produce and dissipate metabolic heat in order to maintain a relatively constant body temperature. Body heat is gained from the environment and is produced by metabolism (i.e., generated through body movement). However, there are many modifying factors that influence body heat, such as absorption of heat from the surrounding environment or clothing. These can impact an individual's vulnerability to heat hazards (Knochel, 1989; Mac \& McCauley, 2017; Lugo-Amador, Rothenhaus, \& Moyer, 2004). Figure 1 below shows several factors that can affect a person's internal body temperature and thus put them at greater risk of HRI.

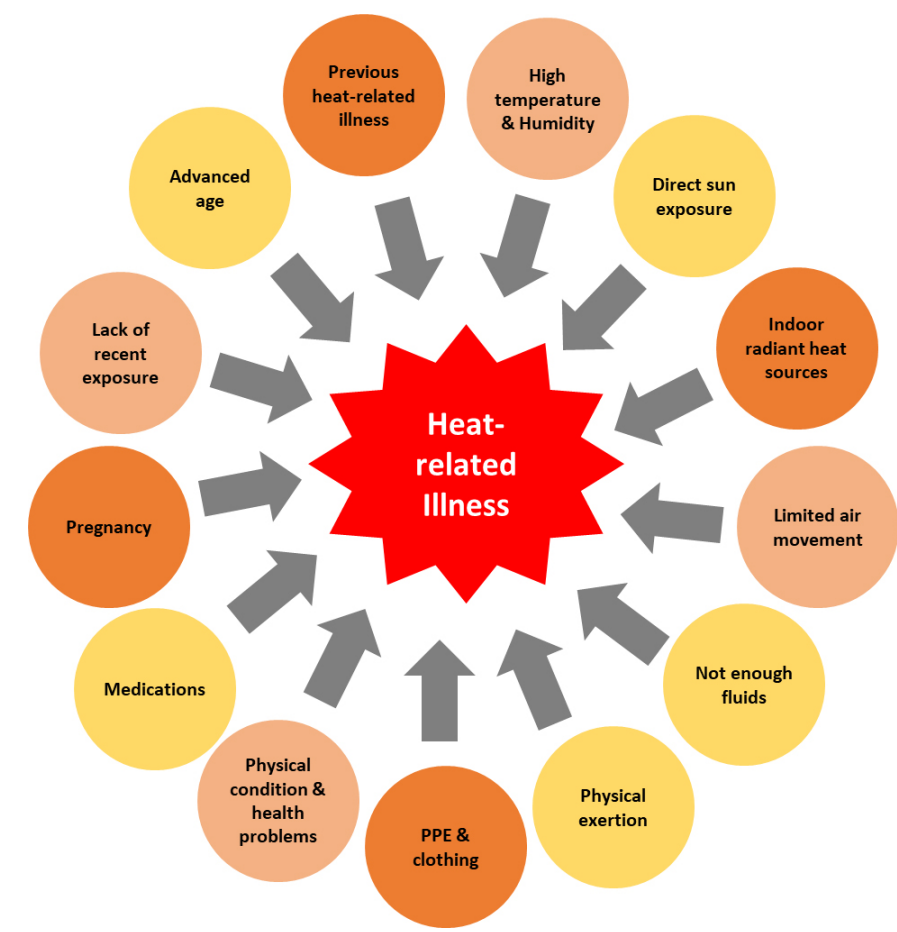

Figure 1. Heat-related illness risk factors.

Credits: adapted from NIOSH, 2016

Some risk factors are not associated with the workplace environment. For example, age, pregnancy, existing heart conditions, and weight/physical fitness are factors that can make a person more susceptible to HRI. In addition to these more general risks associated with HRI, there are also workplace environmental and personal vulnerability factors that can increase HRI susceptibility. Environmental factors include ambient and radiant temperature, direct sun exposure, relative humidity, wind velocity, and clothing 
insulation. Vulnerability factors include the amount of strenuous physical activity performed, ability to take rest breaks during the workday in hot environments, availability and access to proper hydration, and duration of work. Agricultural sectors where workers are faced with a greater combination of these risk factors-and thus are at greater risk for HRI-include field crops, ferneries, and nurseries. Workers who labor in enclosed environments, such as greenhouses, or those that wear full PPE can also be at increased risk.

\section{What can individuals do to prevent HRI?}

Listed below are recommended prevention practices to reduce an individual's risk of HRI. Employers and supervisors are advised to adopt the following as guidelines for their workers to follow throughout the day. Heat-related illness is a serious medical condition that should be treated by medical professionals. However, early recognition and treatment of milder HRI symptoms by on-site nonmedical personnel can contribute to the prevention of exertional heat stroke (Coris et al., 2006; Costrini, 1989). Improving the health and safety of workers can reduce the financial losses employers incur due to workplace injuries and improve the retention, job satisfaction, and productivity of workers overall. Education can also help individuals adopt behaviors that decrease HRI risk, such as acclimatization, drinking more water, wearing proper clothing, and avoiding alcohol prior to heat exposure.

The following HRI prevention practices are recommended (Jacklitsch, 2016; Murphy, n.d.; NIOSH, 2016; PNASH, 2017):

- Wear clothing made of light-colored, cool, breathable material.

- Keep skin dry (applying cornstarch or powder or using absorptive sports or cooling towels may be helpful).

- Allow time for your body to acclimate to the hot environment (typically 10-14 days-acclimatization can decrease after 3 days away from work).

- Do not remain sedentary for long periods when working in the heat.

- Take 15-minute breaks in a cool, shaded place at least every 2 hours.

- Stay hydrated (8 oz of water every 15-30 minutes). Begin adding sports or electrolyte beverages in addition to water after 2 hours of working in the heat.
- Take breaks during strenuous activity. On hotter days, breaks need to be more frequent.

- Do not work alone; implement a buddy system among workers. If you are experiencing symptoms of HRI, never go alone to take a break or rehydrate away from other workers.

- Be mindful of any medications you are taking (check for side effects from heat exposure/sun).

- If you have preexisting health conditions, consult a medical professional before participating in activities in hot or humid environments.

- Avoid alcohol, drugs, energy drinks, and products with large amounts of sugar and caffeine (they can increase dehydration).

\section{Migrant Farmworkers: A Particularly Vulnerable Population}

With its subtropical climate and unique growing conditions, Florida is a "specialty crop" state that produces a variety of fruit and vegetable crops that are not easily grown in other areas. Much of the production of specialty crops is not mechanized, and growers depend on the manual labor of farmworkers to plant, grow, harvest, and pack these products at precise seasonal intervals. In 2016, the agricultural production sector (crops, livestock, forestry, and fisheries) made an overall contribution of $\$ 15.63$ billion to the state's economy (Court, Hodges, \& Rahmani, 2018). The majority of individuals employed to do this strenuous work are immigrant workers, some of whom have H-2A visas that allow them to work temporarily in the United States, while others are undocumented. The crop harvesting performed by migrant and seasonal farmworkers contributes to approximately $60 \%$ of Florida's total farm gate sales (FASS, 2013). Improving safety for agricultural workers can be difficult because of their immigration status and barriers such as language, cultural differences, and the lack of appropriate training materials. Future EDIS publications will address these barriers in more detail and provide help with reaching these audiences.

\section{Summary}

One thing we know about improving workplace safety is that consistent training is crucial for raising awareness, establishing safety practices, and reminding everyone that safety is a workplace culture. Trainings focused on the risks, symptoms, prevention, and specific actions to take in response to heat risks are essential for farm owneroperators, crew leaders, and farmworkers. Researchers at the Southeastern Coastal Center for Agricultural Health 
and Safety (SCCAHS) at the University of Florida have developed and tested trainings that increase awareness and adoption of HRI safety prevention practices among farmworkers (Grzywacz et al., 2019). Extension agents, employers, supervisors, and industry professionals are encouraged to become familiar with the HRI training resources currently available and help connect agricultural workers to these resources.

\section{Additional Resources}

Several resources have been created that present information on HRI in different formats that are relevant to different audiences. These resources include fact sheets, interactive games, heat safety checklists, guidelines for employers, workbooks, and video vignettes.

http://deohs.washington.edu/pnash/heat_illness\#resources (Compiled by the Pacific Northwest Agricultural Safety and Health Center at the University of Washington.)

Farmworker Health \& Safety: Trainer Guide and Workbook (Produced by the Association of Farmworker Opportunity Programs.)

Occupational Heat Exposure (Produced by the US Department of Labor's Occupational Safety and Health Administration.)

\section{References}

Association of Farmworker Opportunity Programs. (2010). Heat stress: Farmworker health and safety. [Trainer Guide and Workbook]. Washington D.C. Retrieved from https:// www.osha.gov/dte/grant_materials/fy09/sh-19485-09/ trainer_guide.pdf

Bureau of Labor Statistics. (2019, March 5). Fatal occupational injuries in Florida - 2018. U.S. Department of Labor. [News Release: 19-143-ATL]. Atlanta, GA. Retrieved from https://www.bls.gov/regions/southeast/news-release/pdf/ fatalworkinjuries_florida.pdf

Center for Disease Control and Prevention [CDC] (n.d.). Heat-related illness. Picture of America Report. Accessed on October 8, 2018. Retrieved from https://www.cdc.gov/ pictureofamerica/pdfs/picture_of_america_heat-related_illness.pdf

Coris, E. E., Walz, S. M., Duncanson, R., Ramirez, A. M., \& Roetzheim, R. G. (2006). Heat illness symptom index (HISI): A novel instrument for the assessment of heat illness in athletes. Southern Medical Journal, 99(4), 340-345.
Costrini, A. (1989). Emergency treatment of exertional heatstroke and comparison of whole body cooling techniques. Medicine and Science in Sports and Exercise, 22(1), $15-18$.

eXtension. (2012). Heat-related illnesses and agricultural producers. Farm and Ranch eXtension in Safety and Health (FReSH) Community of Practice. Retrieved from https://ag-safety.extension.org/ heat-related-illnesses-and-agricultural-producers

Grzywacz, J., Gonzales-Backen, M., Liebman, A., Marin, A., Trejo, M., Gudino, C., Economos, J., \& Tovar-Aguilar, J. A. (2019). Attending to pesticide exposure and heat illness among farmworkers: Results from an attention placebocontrolled evaluation design. Journal of Occupational and Environmental Medicine, 61, 735-742.

Jacklitsch, B., Williams, W. J., Musolin, K., Coca, A., Kim, J. H., \& Turner, N. (2016). NIOSH criteria for a recommended standard: Occupational exposure to heat and hot environments. Department of Health and Human Services, Centers for Disease Control and Prevention, National Institute for Occupational Safety and Health. Publication 2016-106. Cincinnati, OH: U.S. Government Printing Office.

Knochel, J. P. (1989). Heat stroke and related heat stress disorders. Disease-a-Month, 35(5), 306-377.

Mac, V. V. T., \& McCauley, L. A. (2017). Farmworker vulnerability to heat hazards: A conceptual framework. Journal of Nursing Scholarship, 49(6), 617-624.

Morano, L. H., Watkins, S., \& Kintziger, K. (2016). A comprehensive evaluation of the burden of heat-related illness and death within the Florida population. International Journal of Environmental Research and Public Health. 13(6), 551-571. doi: 10.3390/ijerph13060551

Murphy, D. (n.d.). Heat illness and agriculture. Pennsylvania State University College of Agricultural Science Cooperative Extension. Retrieved from https://extension. psu.edu/heat-illness-and-agriculture

Lugo-Amador, N. M., Rothenhaus, T., \& Moyer, P. (2004). Heat-related illness. Emergency Medicine Clinics of North America 22(2), 315-327. doi: 10.1016/j.emc.2004.01.004

National Institute for Occupational Safety and Health [NIOSH]. (2016). Heat Stress - Heat Related Illness. Accessed on October 8, 2018. Retrieved from https://www. cdc.gov/niosh/topics/heatstress/heatrelillness.html 
National Oceanic and Atmospheric Administration

[NOAA]. (2019). Florida, average temperature, January-

December, 1998-2018. Climate at a Glance: Statewide Time

Series. Retrieved on March 12, 2019 from https://www.

ncdc.noaa.gov/cag/

Pacific Northwest Agricultural Safety and Health Center [PNASH]. (2017, June 1). Employer preparedness checklist for heat safety. Department of Environmental \& Occupational Health Sciences. School of Public Health, University of Washington. Retrieved from https://deohs.washington. edu/pnash/sites/deohs.washington.edu.pnash/files/documents/HeatSafetyChecklist.pdf

Perez, M. (2016, May 19). Farmworker dies after complaining of heat exhaustion on bus ride back to Immokalee. Naples Daily News. Retrieved from http://archive. naplesnews.com/news/local/haitian-farmworker-dies-aftercomplaining-of-heat-exhaustian-on-bus-ride-back-toimmokalee-3335e8e7--380144811.html/

Perez, M. (2015, December 22). Report: Farmworker's death should have been prevented. Naples Daily News. Retrieved from http://archive.naplesnews.com/news/crime/ report-farmworkers-death-should-have-been-prevented2738c212-4e00-109c-e053-0100007fd972-363310521.html/

Rao, P. (2007). Heat related illnesses: An occupational health concern for farmworkers. Farmworker Justice and Migrant Clinicians Network. Retrieved from https://www. migrantclinician.org/files/resourcebox/heat_monograph. pdf

Sheridan, S. C., \& Lee, C. C. (2018). Temporal trends in absolute and relative extreme temperature events across North America. Journal of Geophysical Research: Atmospheres, 123(21), 11,889-11,898.

Sund-Levander, M., Forsberg, C., \& Wahren, L. K. (2002). Normal oral, rectal, tympanic and axillary body temperature in adult men and women: A systematic literature review. Scandinavian Journal of Caring Sciences, 16, 122-128. doi:10.1046/j.1471-6712.2002.00069.x 
Table 1. HRI symptoms, causes, and treatment recommendations (sources: Murphy, n.d.; NIOSH 2016).

\begin{tabular}{|c|c|c|c|}
\hline & Signs \& Symptoms & Cause/Physiological Process & Treating Symptoms \\
\hline Heat Rash & $\begin{array}{l}\text { Red, blotchy skin rash } \\
\text { Clusters of pimples/small blisters } \\
\text { Skin feels prickly or itchy } \\
\text { Serious cases may lead to skin } \\
\text { infection. }\end{array}$ & $\begin{array}{l}\text { Excessive sweating } \\
\text { Sweat glands/pores become } \\
\text { clogged and inflamed. }\end{array}$ & $\begin{array}{l}\text { Dry the affected area of skin, and apply } \\
\text { cornstarch or powder. } \\
\text { Work in a cooler, less humid environment } \\
\text { if possible. }\end{array}$ \\
\hline Heat Syncope & $\begin{array}{l}\text { Body temperature still normal } \\
\text { Light-headed or dizzy feeling } \\
\text { Pale complexion } \\
\text { Moist skin } \\
\text { Fainting }\end{array}$ & $\begin{array}{l}\text { Remaining sedentary (sitting or } \\
\text { standing) for long periods of time } \\
\text { Abruptly changing from sitting to } \\
\text { standing position } \\
\text { Increased blood flow to the skin to } \\
\text { release heat; decreased blood flow } \\
\text { to the brain }\end{array}$ & $\begin{array}{l}\text { Lie in a cool area with feet elevated to } \\
\text { improve blood circulation. } \\
\text { Drink liquids to rehydrate. } \\
\text { Consult a medical provider. }\end{array}$ \\
\hline Heat Cramps & $\begin{array}{l}\text { Pain experienced in stomach, } \\
\text { arms, or legs (can be extreme) } \\
\text { Muscle spasms } \\
\text { Excessive sweating and thirst }\end{array}$ & $\begin{array}{l}\text { Loss of body salt, electrolytes, and } \\
\text { fluids due to sweating } \\
\text { Usually results from strenuous } \\
\text { physical activity }\end{array}$ & $\begin{array}{l}\text { Stop activity and hydrate. } \\
\text { DO NOT eat a salt tablet; it may worsen } \\
\text { your HRI symptoms. } \\
\text { Massage affected muscles. }\end{array}$ \\
\hline Heat Exhaustion & $\begin{array}{l}\text { Skin is cool, moist, and pale } \\
\text { Feeling weak, fainting } \\
\text { Headache, dizziness } \\
\text { Mood change, irritability, or } \\
\text { confusion } \\
\text { Nausea, vomiting } \\
\text { Sweating and muscle cramps }\end{array}$ & $\begin{array}{l}\text { Increased blood flow to the skin to } \\
\text { release heat; decreased blood flow } \\
\text { to the brain } \\
\text { Lack of oxygen to the brain } \\
\text { Body is working hard to try to cool } \\
\text { down. }\end{array}$ & $\begin{array}{l}\text { Lie individual down in a cool area with } \\
\text { feet elevated. } \\
\text { Provide plenty of cool fluids to drink. } \\
\text { Call for medical attention. } \\
\text { Remove excess clothing. } \\
\text { Apply cold compresses when available. }\end{array}$ \\
\hline Heat Stroke & $\begin{array}{l}\text { Sudden spike in body } \\
\text { temperature (over } 105^{\circ} \mathrm{F} \text { ) } \\
\text { Sweating has stopped. } \\
\text { Hot, dry skin } \\
\text { Confusion, slurred speech } \\
\text { Seizures } \\
\text { Loss of consciousness; } \\
\text { unresponsive } \\
\text { Coma; death }\end{array}$ & $\begin{array}{l}\text { Internal temperature-regulating } \\
\text { system stops working. } \\
\text { Insufficient blood flow to the brain } \\
\text { Extremely high body temperature } \\
\text { puts vital organs at risk of being } \\
\text { damaged. }\end{array}$ & $\begin{array}{l}\text { First, call } 911 \text { immediately. } \\
\text { Lie individual down in a cool area with } \\
\text { head and shoulders elevated. } \\
\text { Remove excess clothing. } \\
\text { Sponge the individual's body with cool } \\
\text { water (or submerge in a pool of water). } \\
\text { DO NOT give the individual anything to } \\
\text { drink. }\end{array}$ \\
\hline
\end{tabular}

